\title{
Letter: predictors of postoperative complications after selective dorsal rhizotomy
}

\author{
Mohit Agrawal $^{1} \cdot$ Raghu Samala $^{1} \cdot$ Ramesh Sharanappa Doddamani $^{1} \cdot$ P. Sarat Chandra ${ }^{1}$
}

Received: 11 October 2020 / Accepted: 22 October 2020 / Published online: 28 October 2020

(C) Springer-Verlag GmbH Austria, part of Springer Nature 2020

Dear Editor,

In a recently published article by Wach et al. [6] in your esteemed journal, the authors sought to identify the risk factors associated with post-operative complications after selective dorsal rhizotomy (SDR) for spasticity associated with cerebral palsy (CP) in children and adolescents. They analyzed their series of 140 patients undergoing surgery and found risk factors such as obesity for poor wound healing, obesity and thrombocytopenia for surgical site infection (SSI), younger age at surgery for postoperative CSF leak, and non-ambulatory patients for increased analgesia requirement after surgery. We read the findings with great interest and would like to seek some clarifications.

As the authors mentioned, the cutoff for the BMI assessment varies according to the various medical federations and thus the results should be cautiously interpreted. Similarly, the cutoffs for thrombocytopenia and hemoglobin levels which were chosen as 180,000 G/l and $11.2 \mathrm{~g} / \mathrm{dl}$, respectively, seem to be arbitrary. A lower cutoff value might not result in thrombocytopenia as a significant risk factor for SSI.

No mention was made of the follow-up status. It would be interesting to note if there was any detrimental effect of the observed complications on the outcome with respect to spasticity. Such a correlation would further help to guide physicians and prognosticate patients if such a complication does occur.

The authors need to be lauded for presenting the first study of its kind in the field of SDR for CP. The need of the hour are similar studies, performed by centers already experienced with the procedure, exploring the variables affecting outcome and complications for SDR performed for spasticity due to other indications as well. The global burden of spasticity is not only

This article is part of the Topical Collection on Functional Neurosurgery - Other

Ramesh Sharanappa Doddamani drsdramesh@gmail.com

1 Department of Neurosurgery, All India Institute of Medical Sciences, Room No. 716, Neurosciences Centre, New Delhi 110029, India restricted to children with $\mathrm{CP}$, with several other causes like trauma, stroke and neurodegenerative diseases. [1-5] SDR, despite being a destructive procedure, has been shown to be effective in relieving spasticity arising due to such indications. [1-5] The cost-effectiveness of the procedure especially in resource-constrained situations, when compared to other modalities such as spinal cord stimulation, makes it an attractive prospect for directing future research. Identifying parameters that can make the surgery more effective would greatly benefit a larger population suffering from the ill effects of spasticity.

\section{Compliance with ethical standards}

Conflict of interest The authors declare that they have no conflict of interest.

\section{References}

1. Agrawal M, Samala R, Doddamani R, Agrawal D, Chandra SP (2020) The role of selective dorsal rhizotomy in the management of post-traumatic spasticity: systematic review [published online ahead of print, 2020 Feb 5]. Neurosurg Rev. https://doi.org/10. 1007/s10143-020-01255-w

2. Agrawal M, Garg K, Mishra S, Doddamani R, Chandra PS (2020) Letter to the editor regarding "Selective dorsal rhizotomy for spasticity of genetic etiology". Childs Nerv Syst 36(9):1825-1825

3. Gump WC, Mutchnick IS, Moriarty TM (2013) Selective dorsal rhizotomy for spasticity not associated with cerebral palsy: reconsideration of surgical inclusion criteria. Neurosurg Focus 35:E6

4. Lohkamp L, Coulter I, Ibrahim GM (2020) Selective dorsal rhizotomy for spasticity of genetic etiology. Childs Nerv Syst 36:1357-1365

5. Meena R, Doddamani RS, Agarwal N, Sawarkar D, Agrawal D (2019) Simultaneous microsurgical DREZ-otomy of cervical and lumbosacral spine for tetra-spastic status with double hemiparesis. J Periph Nerve Surg 3(1):15-19

6. Wach J, Yildiz ÖC, Sarikaya-Seiwert S, Vatter H, Haberl H (2020) Predictors of postoperative complications after selective dorsal rhizotomy [published online ahead of print, $2020 \mathrm{Jul} 20$ ]. Acta Neurochir. https://doi.org/10.1007/s00701-020-04487-3

Publisher's note Springer Nature remains neutral with regard to jurisdictional claims in published maps and institutional affiliations. 